\title{
Occupational factors and low back pain: a cross-sectional study of Bangladeshi female nurses
}

Shubrandu S. Sanjoy', Gias U. Ahsan', Hayatun Nabi ${ }^{1}$, Ziaul F. Joy² and Ahmed Hossain*

\begin{abstract}
Background: The suffering from low back pain (LBP) is very common among nurses. The high prevalence rates of LBP are observed in many countries. Many back injuries are due to individual and work-related factors. Our aim is to investigate whether there is an association of occupational factors with LBP among the female nurses who are currently working in tertiary hospitals of Bangladesh.

Methods: We conducted a cross-sectional study with 229 female nurses from two selected tertiary hospitals in Bangladesh. Data was collected through face-to-face interview using a standard structured questionnaire on four different measures of LBP along with questions on socio-demographic, occupational factors, physical and psychological factors.

Results: Prevalence rates of LBP that lasted for at least 1 day, chronic LBP, intense pain and sought medical care because of LBP during the last 12 months were $72.9,31.8,24.4$ and 36.2\%, respectively. The multiple logistic regression analyses indicates that insufficient supporting staffs, overtime working hours and manual lifting in a working environment are associated with LBP. Besides, age and parity are found positively associated with chronic LBP.

Conclusion: The prevalence of LBP among nurses in Bangladesh is high and should be actively addressed. Certain occupational factors play a key role in developing LBP among nurses. Nurses to patients ratio should be taken into consideration to reduce the occurrence of LBP among nurses employed in hospitals.
\end{abstract}

Keywords: Low back pain, Hospital occupational factors, Nurses, Bangladesh

\section{Background}

Low back pain (LBP) is defined as pain or discomfort, which also known as lumbago, occurs below the costal margin and above the gluteal fold [1,2]. LBP is one of the leading public health problems with over $80 \%$ of the world population reporting LBP at some point in their life [3]. The prevalence of LBP is high especially in low and middle-income countries [4-6].

LBP is a common cause of morbidity in hospital health care workers. Nursing personnel, among the occupational groups within the health service, is more vulnerable to LBP [7]. A study in the USA indicates that nursing

\footnotetext{
*Correspondence: ahmed.hossain@utoronto.ca

1 Department of Public Health, North South University, Bashundhara, Dhaka 1229, Bangladesh

Full list of author information is available at the end of the article
}

is one of the riskiest occupations for back pains, and it has the highest incidence of all types of nonfatal workrelated injuries [8]. The risk factors of LBP among nurses are usually multifactorial, probably because the job needs a mixture of physically (such as manual handling of patients or medical equipment) and mentally demanding tasks (such as dealing with a crisis). Westgaard also discussed the effect of physical and mental stressors on muscle pain [9].

Poor working conditions bear some of the responsibilities of LBP in nursing personnel. Nurses in any department of a hospital are often administered with many unplanned works with varied tasks and responsibilities [10]. It is reported a strong association with LBP in nurses and postures in physical work such as the manual lifting of heavy objects or transferring patients and 
medical equipment $[11,12]$. Many of the previous studies conducted to identify the roles of individual and occupational factors on LBP among nurses [13-16]. Serranheira et al. [17] described the prevalence increases and peaks between the ages of 35 and 55 years. Besides, lack of physical exercise is an important associated risk factor of LBP among the nurses. Lack of exercise renders inadequate flexibility and weak muscles in the back, pelvis, and thighs, causing increases of LBP [18-20]. Moreover, a number of studies indicated an association between work-related factors and LBP among the nursing staffs $[14,21,22]$.

Nurses in developing countries have a higher incidence of occupation-related back pain due to lack of equipment and designs of work [4-6]. The intensity of LBP has rarely been taken into consideration in Bangladesh. It is important to find the occupational risk factors of LBP among nurses that will help to take necessary steps to minimize the risk of LBP and ensure safety occupational environment. We pay attention to different measures of LBP following Ozguler et al. [23]. To contribute to the present knowledge of LBP, we have carried out a cross-sectional study with the aim of identifying occupational risk factors in the Bangladeshi female working nurses.

\section{Data and methods}

\section{The data}

A cross-sectional study was conducted at Sylhet MAG Osmani Medical College \& Hospital (public) and Jalalabad Ragib Rabeya Medical College \& Hospital (private) in Sylhet, Bangladesh. On November 10, 2016, we found there was a total of 453 registered female nurses working in the two tertiary hospitals. Among which 245 and 208 female nurses were working in the public and private hospitals, respectively. As there are currently no studies that report the prevalence of LBP among nurses in Bangladesh, we consider the prevalence of LBP is $50 \%$ to estimate the sample size. At a confidence level of $95 \%$, and margin error of $5 \%$, the maximum sample size was calculated as 384 nurses. Using the finite population correction we have the required sample size is $\frac{384}{1+384 / 453}$ i.e. 233.

\section{Low back pain measures}

Information on LBP was collected using a questionnaire with a diagram of the lower back area. We measured LBP by asking four questions following Feng et al. [16]. The first question about LBP (primarily pain, numbness, tingling, aching, stiffness, or burning of the lower back area) considers the pain that lasts for at least 1 day during the past 12 months. The other three questions of LBP measures are a chronic pain (daily pain for at least 3 months), intense pain (an intensity of pain score 6 and above on visual an analogue scale from 0 to 9 ) and seeking medical care (visit to a doctor or physiotherapist because of LBP during the last 12 months). Thus, a total of four different measures were used to define LBP.

\section{Independent variables}

We designed a questionnaire to obtain information on date of birth, height, weight, date of survey, marital status (single or married), parity (yes or no), hospital (public or private), designation (head nurse or ordinary nurse), department (medicine, surgery, pediatric and obstetrics and gynecology), monthly family income $(<25,000 \mathrm{BDT}$, 25,000-35,000 BDT and $>35,000$ BDT), average daily sleep duration, weekly working hours $(\leq 40$ or $>40 \mathrm{~h}$ ), prolong standing (1-2 or $2-3 \mathrm{~h}$ ), manual lifting (yes or no), enough supporting staffs (yes or no) and regular physical exercise (yes or no). The duration of working was categorized as $<5,5-10$ and $>10$ years. The overall job satisfaction was assessed by a question "Considering everything (coworkers, supervisor, availability of equipments) in your department, how satisfied are you with your job?". The question was rated on a five-point Likert scale, ranging from 1 (strongly agree) to 5 (strongly disagree). We classify the sleep duration as short sleep duration $(<6 \mathrm{~h})$ and adequate sleep duration ( $\geq 6 \mathrm{~h}$ ). We consider age in years from the date of births and we calculate body mass index (BMI) from height and weight. The age and BMI were managed as continuous variables. From December to January 2015, inspectors who were familiar with the questionnaire went to the two tertiary hospitals and taking face-to-face interview from the female nurses who are currently working in those hospitals. Any question or confusion from the participants was clarified to ensure that everyone understood all of the items. The complete questionnaires were reviewed for quality control.

\section{Statistical analysis}

We analyzed the data using software R. We calculated the descriptive statistics for all of the variables which include continuous variables (presented as a mean and standard deviation) and categorical variables (presented as frequencies and percentages). The association between potential risk factors and LBP measures were modeled by separate multivariate logistic regressions with a backward selection procedure. The results were reported by adjusted odds ratios (ORs) and corresponded 95\% confidence intervals (CIs). A $p$ value less than 0.05 was considered statistically significant. Later, we investigate whether age is potential for confounding in the apparent relationship between an occupational factor and any of LBP measures. We found age relates to both LBP and any of the factors like designation, duration of working hours, BMI, parity, etc. Therefore to avoid biased results when examining the association between factors and LBP, we 
stratify age into two groups and considered modeling strategies with the nurses who are less than 40 years old.

\section{Results}

\section{Characteristics of the study participants}

The data comprised of 229 registered female working nurses from two tertiary hospitals: one of which is public and another one is private. The nurses were aged 22-56 years (mean 33.54 years). The baseline characteristics of the participants, such as designation, marital status, parity, family income, duration of working hours, prolong standing, manual lifting, supporting staff, physical exercise, sleeping hours and job satisfaction, are given in Table 1. The four different LBP measures are indicated a varied range of prevalence rates which is shown in Table 1 . The most prevalence measure (72.9\%) was pain that lasts for at least 1 day, which represents a broad category. Moreover, $31.8 \%$ nurses were found with chronic LBP; $36.2 \%$ reported having sought medical care in the past 12 months because of LBP, and $24.4 \%$ complained to suffer from intense pain. Among the nurses $73.8 \%$ were married, $59.8 \%$ had no children, $20.5 \%$ worked at least 10 years on the current job, and 59.3\% worked overtime (i..e., $>40 \mathrm{~h}$ per week). Compared with the private hospital, the tertiary public hospital had a higher prevalence of LBP. The age and BMI of the nurses are considered as continuous variables, and the mean and standard deviation are given in Table 2 . The Table 2 shows that the average age of nurses who were suffering from chronic LBP is 37.7 ( $\mathrm{SD}=7.8$ ) years. It appears from the Table 2 that older female nurses suffered more with LBP compared to younger female nurses (e.g., the average age of the nurses having chronic pain is 37.79 years whereas the average age is 31.55 years for the nurses who don't

Table 1 The baseline characteristics of the participants $(n=229)$

\begin{tabular}{|c|c|c|c|c|c|}
\hline Variables & Categories & $\begin{array}{l}\text { LBP for } \geq 1 \text { day } \\
\text { ( } n=167,72.9 \%) \\
\text { Yes }\end{array}$ & $\begin{array}{l}\text { Chronic LBP }(n=73, \\
31.9 \%) \\
\text { Yes }\end{array}$ & $\begin{array}{l}\text { Intense pain ( } n=56 \\
24.5 \% \text { ) } \\
\text { Yes }\end{array}$ & $\begin{array}{l}\text { Seeking medical care } \\
(\mathrm{n}=83,36.2 \%) \\
\text { Yes }\end{array}$ \\
\hline \multirow[t]{2}{*}{ Tertiary hospital } & Private (105) & 67 (63.8\%) & $14(13.3 \%)$ & $10(9.5 \%)$ & $30(28.6 \%)$ \\
\hline & Public (124) & $100(80.7 \%)$ & $59(47.6 \%)$ & $46(37.1 \%)$ & $53(43.7 \%)$ \\
\hline \multirow[t]{2}{*}{ Designation } & Head nurse (55) & $17(30.9 \%)$ & $9(16.4 \%)$ & $8(14.6 \%)$ & $12(21.8 \%)$ \\
\hline & Ordinary nurse (174) & $150(86.2 \%)$ & $64(36.8 \%)$ & $52(29.89 \%)$ & $71(40.8 \%)$ \\
\hline \multirow[t]{2}{*}{ Marital status } & Single $(60)$ & $38(63.3 \%)$ & $8(13.3 \%)$ & $4(6.66 \%)$ & $15(25.00 \%)$ \\
\hline & Married (169) & $129(76.3 \%)$ & $65(38.6 \%)$ & $52(30.7 \%)$ & $68(40.3 \%)$ \\
\hline \multirow[t]{2}{*}{ Parity } & No $(92)$ & $55(59.8 \%)$ & $17(18.5 \%)$ & $6(6.5 \%)$ & $24(26.1 \%)$ \\
\hline & Yes (137) & $112(81.8 \%)$ & $56(40.9 \%)$ & $50(36.5 \%)$ & $59(43.1 \%)$ \\
\hline \multirow[t]{3}{*}{ Family income } & $<25,000 \mathrm{TK}(38)$ & $28(73.68 \%)$ & $13(34.2 \%)$ & $8(21.1 \%)$ & $12(31.9 \%)$ \\
\hline & $25,000-35,000$ TK (84) & $58(69.1 \%)$ & $21(25.0 \%)$ & $12(14.3 \%)$ & $26(30.9 \%)$ \\
\hline & $>35,000 \mathrm{TK}(107)$ & $81(75.7 \%)$ & $39(36.5 \%)$ & $22(20.6 \%)$ & $45(42.1 \%)$ \\
\hline \multirow[t]{3}{*}{ Duration of working } & $<5$ years $(143)$ & $102(71.3 \%)$ & $40(27.9 \%)$ & $31(21.7 \%)$ & 48 (33.6\%) \\
\hline & $5-10$ years (39) & $24(61.4 \%)$ & $4(10.3 \%)$ & $3(7.7 \%)$ & $10(25.6 \%)$ \\
\hline & $>10$ years $(47)$ & $41(87.3 \%)$ & $29(61.7 \%)$ & $22(46.8 \%)$ & $25(53.2 \%)$ \\
\hline \multirow[t]{2}{*}{ Weekly working hours } & Overtime (93) & $76(81.7 \%)$ & $37(39.8 \%)$ & $21(22.6 \%)$ & $42(45.2 \%)$ \\
\hline & Regular (136) & $91(66.9 \%)$ & $36(26.5 \%)$ & $35(25.7 \%)$ & $41(30.2 \%)$ \\
\hline \multirow[t]{2}{*}{ Prolong standing } & $1-2 \mathrm{~h}(128)$ & $86(67.2 \%)$ & $29(22.7 \%)$ & $25(19.5 \%)$ & $38(29.7 \%)$ \\
\hline & $2-3 h(101)$ & $81(80.2 \%)$ & $44(43.6 \%)$ & $31(30.7 \%)$ & $45(44.6 \%)$ \\
\hline \multirow[t]{2}{*}{ Manual lifting } & Yes (176) & $127(72.2 \%)$ & $60(34.1 \%)$ & $49(27.8 \%)$ & $67(38.1 \%)$ \\
\hline & No (53) & $40(7.5 \%)$ & $13(24.5 \%)$ & $7(13.2 \%)$ & $16(30.2 \%)$ \\
\hline \multirow[t]{2}{*}{ Supporting staff } & Yes (94) & $44(47.3 \%)$ & $15(16.2 \%)$ & $13(14.0 \%)$ & $21(22.6 \%)$ \\
\hline & No (135) & $122(90.4 \%)$ & $58(43.0 \%)$ & $43(31.9 \%)$ & $62(45.9 \%)$ \\
\hline \multirow[t]{2}{*}{ Physical exercise } & Yes (36) & $26(72.2 \%)$ & $10(27.8 \%)$ & $8(22.2 \%)$ & $9(25.0 \%)$ \\
\hline & No (193) & $141(73.1 \%)$ & $58(30.1 \%)$ & $48(24.8 \%)$ & $74(38.3 \%)$ \\
\hline \multirow[t]{2}{*}{ Sleeping hours } & $<6$ h (118) & $96(81.4 \%)$ & $53(44.9 \%)$ & 40 (33.9\%) & $55(46.6 \%)$ \\
\hline & $\geq 6 \mathrm{~h}(111)$ & $71(64.0 \%)$ & $20(18.0 \%)$ & $16(14.4 \%)$ & $28(25.2 \%)$ \\
\hline \multirow[t]{3}{*}{ Job satisfaction } & Strongly agree (47) & $38(80.9 \%)$ & $21(44.7 \%)$ & $18(38.3 \%)$ & $22(46.8 \%)$ \\
\hline & Agree (123) & $92(74.8 \%)$ & $44(35.7 \%)$ & $30(24.4 \%)$ & 45 (36.6 s \%) \\
\hline & Neither (59) & $37(62.7 \%)$ & $8(13.6 \%)$ & $8(13.6 \%)$ & $16(27.1 \%)$ \\
\hline
\end{tabular}


Table 2 Mean (standard deviation) of age and BMI corresponds to LBP measurements

\begin{tabular}{|c|c|c|c|c|c|c|c|c|}
\hline & LBP lasted & $\geq 1$ day & Chronic LE & & Intense pa & & Seeking me & I care \\
\hline & Yes & No & Yes & No & Yes & No & Yes & No \\
\hline Age (years) & $34.72(8.2)$ & $30.37(6.6)$ & $37.79(7.8)$ & $31.55(7.3)$ & $37.79(7.4)$ & $32.26(7.8)$ & $37.79(7.7)$ & $32.54(8.04)$ \\
\hline BMI $\left(\mathrm{kg} / \mathrm{m}^{2}\right)$ & 23.95 (3.4) & $22.00(2.9)$ & $24.36(3.0)$ & $22.99(3.5)$ & $24.98(3.3)$ & $22.92(3.3)$ & $23.86(23.1)$ & $3.05(3.60)$ \\
\hline
\end{tabular}

have chronic pain). The average BMI of the nurses with chronic LBP was found $24.3(\mathrm{SD}=3.0) \mathrm{kg} / \mathrm{m}^{2}$. The BMI indicates that weighted female nurses complained more on LBP compared to those who have less BMI (e.g., the average BMI is $24.36 \mathrm{~kg} / \mathrm{m}^{2}$ for the nurses having chronic pain whereas the value is $22.99 \mathrm{~kg} / \mathrm{m}^{2}$ for the group of no chronic pain).

\section{Significant risk factors for different LBP measures}

We fit multivariable backward stepwise logistic regression models with each of LBP measures after adjusting all the occupational and individual risk factors. Table 3 shows the results of significant factors associated with each of the four measures of LBP. It appears that the different measures of LBP were found to be associated with different potential factors. Three occupational factors that include lack of supporting staffs $(\mathrm{OR}=2.72)$, working overtime $(\mathrm{OR}=1 / 0.38$, i.e., 2.63$)$ and having manual lifting in the daily job $(\mathrm{OR}=1 / 0.365$, i.e., 2.74$)$ were found an association with different measures of LBP. The results indicate that the nurses in a department with the lack of supporting staffs are 2.74 times more likely to have the chronic back pain than the nurses who are working with adequate supporting staffs. Moreover, the nurses working overtime are 2.63 times more likely to have the chronic pain than the nurses working a regular hours. Age $(\mathrm{OR}=1.08)$ is also found significant to develop chronic pain which indicates $8 \%$ increase in the risk of having chronic back pain by 1 year increase of age. Another individual factor parity is found positively associated with intense pain and the odds ratio indicates that nurses with children are 4.07 times more likely to have intense back pain in their lifetime than the nurses who do not have children. We considered age as a confounding variable because it influences both LBP and the other independent variables like designation, duration of working hours, BMI, parity, etc. To avoid age as a confounding variable, we considered data from nurses less than 40 years of age. We fit a multivariate backward stepwise logistic regression model with each of the four LBP measures after adjusting all the occupational and individual risk factors. Table 4 shows the results of significant factors associated with each of the four measures of LBP with nurses less than 40 years of age. The results indicate that lack of supporting staffs is positively related with each of the LBP measures. Two other work-related factors that include manual lifting of patients or equipments in their work environment and working overtime are found associated with LBP. Public hospital $(\mathrm{OR}=4.88)$ nurses were found more affected by the LBP, especially

Table 3 Association of different LBP related measures with risk factors identified from multivariate backward stepwise logistic regression (Overall)

\begin{tabular}{|c|c|c|c|c|c|c|}
\hline LBP measures & Significant risk factors & Reference & OR & LCL & UCL & $p$ value \\
\hline \multirow[t]{5}{*}{ LBP for $\geq 1$ day } & Age & & 1.094 & 1.003 & 1.202 & 0.048 \\
\hline & Hospital-public & Private & 0.268 & 0.062 & 1.098 & 0.071 \\
\hline & parity-yes & No & 3.342 & 1.148 & 9.947 & 0.027 \\
\hline & Working hours-regular & Overtime & 0.475 & 0.224 & 0.974 & 0.046 \\
\hline & Supporting staff-no & Yes & 10.67 & 4.884 & 25.114 & $<0.001$ \\
\hline \multirow[t]{4}{*}{ Chronic LBP } & Age & & 1.08 & 1.01 & 1.159 & 0.026 \\
\hline & Working hours-regular & Overtime & 0.38 & 0.181 & 0.774 & 0.008 \\
\hline & Manual lifting-no & Yes & 0.365 & 0.149 & 0.842 & 0.022 \\
\hline & Supporting staff-no & Yes & 2.722 & 1.301 & 5.914 & 0.009 \\
\hline \multirow[t]{2}{*}{ Intense pain } & Parity-yes & No & 4.068 & 1.118 & 20.238 & 0.05 \\
\hline & Manual lifting-no & Yes & 0.29 & 0.102 & 0.731 & 0.012 \\
\hline \multirow[t]{3}{*}{ Seeking medical care } & Working hours-regular & Overtime & 0.485 & 0.257 & 0.904 & 0.023 \\
\hline & Supporting staff-no & Yes & 2.788 & 1.431 & 5.596 & 0.003 \\
\hline & Manual lifting-no & Yes & 0.487 & 0.225 & 1.008 & 0.058 \\
\hline
\end{tabular}


Table 4 Association of different LBP related measures with risk factors identified from multivariate backward stepwise logistic regression when age $\leq \mathbf{4 0}$ years

\begin{tabular}{|c|c|c|c|c|c|c|}
\hline LBP measures & Significant risk factors & Reference & OR & $\mathrm{LCL}$ & UCL & $p$ value \\
\hline \multirow[t]{3}{*}{ LBP for $\geq 1$ day } & Parity-yes & No & 3.088 & 1.002 & 9.91 & 0.052 \\
\hline & Working hours-regular & Overtime & 0.426 & 0.182 & 0.955 & 0.042 \\
\hline & Supporting staff-no & Yes & 7.158 & 3.186 & 17.234 & $<0.001$ \\
\hline \multirow[t]{4}{*}{ Chronic LBP } & Hospital-public & Private & 4.889 & 1.265 & 20.759 & 0.024 \\
\hline & Working hours-regular & Overtime & 0.265 & 0.108 & 0.622 & 0.002 \\
\hline & Manual lifting-no & Yes & 0.366 & 0.119 & 0.988 & 0.052 \\
\hline & Supporting staff-no & Yes & 2.371 & 0.986 & 5.961 & 0.057 \\
\hline Intense pain & Manual lifting-no & Yes & 0.189 & 3.951 & 0.655 & 0.017 \\
\hline \multirow[t]{2}{*}{ Seeked medical care } & Working hours-regular & Overtime & 0.399 & 0.189 & 0.828 & 0.014 \\
\hline & Supporting staff-no & Yes & 2.26 & 1.05 & 4.998 & 0.039 \\
\hline
\end{tabular}

with chronic pain. The results from the Table 4 are found consistent with the results of Table 3. Therefore, it appears that mainly three occupational factors, lack of supporting staffs, manual lifting and overtime working hours, are found significant to develop LBP.

\section{Discussions}

Nurses in hospitals of Bangladesh are commonly found with low back pain that occurs not because of accidents, but because of few occupational factors. We study the LBP among nursing staffs because of its professional, economic and social burden. Without knowing the occupational factors that cause LBP might severely hamper effective prevention and management. Based on the female nurses in the previous 12 months, the prevalence rates for pain lasts for at least 1 day, intense pain, chronic pain, and seeking medical care were 73.0, 24.4, 31.8, and $36.2 \%$, respectively. The results indicate higher prevalence of LBP in Bangladeshi nurses than the Taiwanese female nurses where the prevalence rates for pain lasting for at least one day, seeking of medical care, intense pain, sick leave, and chronic pain were 66.0, 43.9, 38.1, 10.7 , and $8.6 \%$, respectively [16]. This result indicates that the prevalence rate of LBP among nurses in Bangladesh is high and more active steps need to be taken to address this problem.

In this study, we found three occupational factors are mainly associated with LBP measures. The significant risk factors are a lack of supporting staff, manual lifting and overtime working hours, whereas some demographic factors like age and parity were related with different LBP measures. These findings are found consistent with previous findings [24, 25]. Therefore, it is important to increase nursing staffs by taking consideration of nurse to patient ratio. Insufficient supporting staffs in a hospital might increase the frequency of manual handling per nurse as well work overtime and in turn lead to greater risk of LBP. One of the limitations of this study to use of cross-sectional design which might create exaggeration of some relationships noted in this study since the study subjects with LBP might be inclined to over-report their psychosocial load or physical exertion. The study involves only two tertiary hospitals, which means additional studies are needed to draw a more precise conclusion in developing LBP among the nurses of Bangladesh.

\section{Conclusion}

The study indicates that the prevalence rate of LBP among the female nurses in Bangladesh is high and more operative steps should be taken to address this problem. The attention should focus on increase supporting staffs, reduce weekly working hours and lessen the frequency of manual lifting in the work environment.

\section{Abbreviations \\ LBP: Iow back pain; BMI: body mass index; OR: odds ratio; Cl: confidence interval; SD: standard deviation.}

\section{Authors' contributions}

SS participated in study conception, design and coordination, data interpretation and drafted the manuscript. GUA and HTN reviewed the manuscript and helped to draft the manuscript. ZFJ helped in data collection and questionnaire design. AH contributed in study conception, design, performed statistical analysis and helped to draft the manuscript. All authors read and approved the final manuscript.

\section{Author details}

${ }^{1}$ Department of Public Health, North South University, Bashundhara, Dhaka 1229, Bangladesh. ${ }^{2}$ Department of Genetic Engineering \& Biotechnology, Shahjalal University of Science and Technology, Sylhet, Bangladesh.

\section{Acknowledgements}

All the authors acknowledge Sylhet MAG Osmani Medical College \& hospital, Jalalabad Ragib Rabeya Medical College \& Hospital and the participants for providing us the information to conduct the study. We would also like to thank two anonymous reviewers and the editor for insightful comments that improved the presentation and clarity of our manuscript.

Competing interests

The authors declare that they have no competing interests. 


\section{Availability of data}

Click here for the data file http://individual.utoronto.ca/ahmed_3/index_files/ data/data.html.

\section{Ethical approval}

Ethical approval for the study protocol was obtained from the North South University Review Committee and the two tertiary hospitals. A written informed consent was obtained from all the study participants. The members of the ethics committee were:

Dr. Akhter Hossain, Chair, Department of Public Health, North South University.

Dr. G. U. Ahsan, Dean, School of Health and Life Sciences, North South University. College

Dr. Md. Abdus Salam, Deputy Director, Sylhet MAG Osmani Medical

Dr. Abed Hossain, Director, Jalalabad Ragib Ali Medical College.

\section{Publisher's Note}

Springer Nature remains neutral with regard to jurisdictional claims in published maps and institutional affiliations.

Received: 6 July 2016 Accepted: 25 April 2017

Published online: 28 April 2017

\section{References}

1. Owoeye IO. The human back: physical examination and physical assessment. JNMRT. 1999;4(7):1-6.

2. Waheed A. Effect of interferential therapy on low back pain and its relevance to total lung capacity. JNMRT. 2003;8(2):6-18.

3. Walker BF. The prevalence of low back pain: a systematic review of the literature from 1966 to 1998. J Spinal Disord. 2000;13(3):20517.

4. Hoy D, Toole MJ, Morgan D, et al. Low back pain in rural Tibet. Lancet. 2003;361:225-6.

5. Jin K, Sorock GS, Courtney TK. Prevalence of low back pain in three occupational groups in Shanghai, Peoples Republic of China. J Saf Res. 2004;35:23-8.

6. Ory FG, Rahman FU, Katagade V, et al. Respiratory disorders, skin complaints, and low-back trouble among tannery workers in Kanpur, India. Am Industrial Hyg Assoc J. 1997;58:740-6.

7. Cunninham C, Flynn T, Blake C. Low back pain and occupation among irish health service workers. Occup Med. 2006:56(7):447-54

8. Knibbe J, Friele R. Prevalence of back pain and characteristics of the physical workload on community nurses. Ergonomics. 1996:39:186198.

9. Westgaard $\mathrm{RH}$. Effect of physical and mental stressors on muscle pain. Scand J Work Environ Health. 1999:25:1924.
10. Davis KG, Heaney CA. The relationship between psychosocial work characteristics and low back pain: underlying methodological issues. Clin Biomech. 2000;15:389406.

11. Macfarlane GJ, Thomas E, Papageorgiou AC. Employment and physical work activities as predictors of future low back pain. Spine. 1997;22:11431149.

12. Freimann T, Coggon D, Merisalu E, Animagi L, Paasuke M. Risk factors for musculoskeletal pain amongst nurses in Estonia: a cross-sectional study. BMC Musculoskelet Disord. 2013:14:334.

13. Chiou WK, Wong MK, Lee YH. Epidemiology of low back pain in Chinese nurses. Int J Nurs Stud. 1994;31:361-8.

14. Smedley J, Egger P, Cooper C, Coggon D. Manual handling activities and risk of low back pain in nurses. Occup Environ Med. 1995;52:160-3.

15. Trinkoff AM, Lipscomb JA, Geiger-Brown J, Storr CL, Brady BA. Perceived physical demands and reported musculoskeletal problems in registered nurses. Am J Prev Med. 2003;24:270-5.

16. Feng CK, Chen ML, Mao IF. Prevalence of and risk factors for different measures of low back pain among female nursing aides in Taiwanese nursing homes. BMC Musculoskelet Disord. 2007;8:52.

17. Serranheira F, Cotrim T, Rodrigues V, et al. Nurses from a working tasks and MSDs back symptoms: resultsnational survey. Work. 2012;41(Suppl 1):2449-51.

18. Schlossmacher R, Amaral F. Low back injuries related to nursing professionals working conditions: a systematic review. Work. 2012;41(Suppl 1):5737-8.

19. Warnakulasuriya SS, Peiris-John RJ, Coggon D, et al. Musculoskeletal pain in four occupational populations in Sri Lanka. Occup Med. 2012;62(4):269-72.

20. Karahan A, Kav S, Abbasoglu A, et al. Low back pain: prevalence and associated risk factors among hospital staff. J Adv Nurs. 2009;65(3):516-24.

21. Alexopoulos EC, Burdorf A, Kalokerinou A. Risk factors for musculoskeletal disorders among nursing personnel in Greek hospitals. Int Arch Occup Environ Health. 2003;76:289-94.

22. Josephson M, Vingard E. Workplace factors and care seeking for low-back pain among female nursing personnel. Scand J Work Environ Health. 1998;24(6):465-72.

23. Ozguler A, Leclerc A, Landre MF, Pietri-Taleb F, Niedhammer I. Individual and occupational determinants of low back pain according to various definitions of low back pain. J Epidemiol Community Health. 2000:54:215-20.

24. Lin PH, Tsai YA, Chen WC, Huang SF. Prevalence, characteristics, and workrelated risk factors of low back pain among hospital nurses in Taiwan: a cross-sectional survey. Int J Occup Med Environ Health. 2012;25(1):4150. doi:10.2478/s13382-012-0008-8.

25. Violante FS, Fiori M, Fiorentini C, Risi A, Garagnani G, Bonfiglioli R, et al. Associations of psychosocial and individual factors with three different categories of back disorder. J Occup Health. 2004;46:100-8.

\section{Submit your next manuscript to BioMed Central and we will help you at every step:}

- We accept pre-submission inquiries

- Our selector tool helps you to find the most relevant journal

- We provide round the clock customer support

- Convenient online submission

- Thorough peer review

- Inclusion in PubMed and all major indexing services

- Maximum visibility for your research

Submit your manuscript at www.biomedcentral.com/submit
Biomed Central 